\title{
Effect of grain boundary misorientation on discontinuous precipitation in an AZ91 alloy
}

\author{
H AZZEDDINE*, S ABDESSAMEUD, B ALILI, Z BOUMERZOUG ${ }^{\dagger}$ and D BRADAI \\ Faculty of Physics, University of Sciences and Technology Houari Boumediene, BP 32 El-Alia, Bab-Ezzouar, \\ Algiers, Algeria \\ ${ }^{\dagger}$ Department of Metallurgy, University of Biskra, B.P. 145, 07000, Algeria
}

MS received 4 August 2009; revised 1 February 2011

\begin{abstract}
A scanning electron microscopy (SEM)-based electron backscatter diffraction (EBSD) analysis showed that the discontinuous precipitation (DP) reaction rate was dependent on the geometry of the grain boundary in Mg-9Al-1Zn (wt.\%) alloys. DP converted a supersaturated solid solution, $\delta_{0}$ (magnesium (Mg)rich solid solution), into a two-phase $\delta+\gamma$ aggregate, with $\delta$ being a precipitated $\operatorname{Mg}_{17} \mathbf{A l}_{12}$ (intermetallic phase) behind a migrating reaction front. The near-special grain boundary was rather inactive, whereas most of the random high-angle boundaries promoted the reaction. Prior deformation (hot rolling to achieve up to $80 \%$ thickness reduction) had no effect on the frequency of special-grain boundaries.
\end{abstract}

Keywords. AZ91 alloy; precipitation; kinetics; GBCD; EBSD.

\section{Introduction}

During the last decades, interest in Mg-based alloys has increased worldwide due to their low density and highspecific strength that make them useful for applications in the aerospace, aircraft and automotive industries. AZ91 (Mg-9Al-1Zn-0.2Mn wt.\%) is the most popular $\mathrm{Mg}$ alloy, being used in approximately $90 \%$ of all $\mathrm{Mg}$-cast products (Lesuer and Kipoures 1995). AZ91 alloys are strengthened by precipitation hardening even if the resulting hardness is lower than that of Al-based alloys. The principal reason for the poor structural hardening is discontinuous precipitation (DP), which originates in the grain boundaries and expands to the adjacent grains. The lamellar-cellular morphology of this reaction is responsible for the poor corrosion resistance of the alloy. Many studies have investigated the morphology and kinetics of this reaction with the aim of retarding or even inhibiting its occurrence (Azzeddine et al 2009).

Grain boundary misorientation refers to the crystallographic orientation relationship between neighbouring grains of the same phase (Randle 1993). It is one of the most important parameters governing the intrinsic properties - energy, diffusivity and mobility - and controls the solid-state transformation, such as the DP reaction that originates in or evolves from the grain boundaries. Very few studies have investigated the correlation between the grain boundary character distribution (GBCD) and massive

\footnotetext{
*Author for correspondence (azehibou@ yahoo.fr)
}

phase transformation in industrial metallic materials (Shibayanagi et al 1990; Matsuoka et al 1994; Bischoff et al 1998).

Bradai et al (2002) previously attempted to correlate the grain boundary misorientation with the DP reaction in a binary model (and undeformed) $\mathrm{Mg}-\mathrm{Al}$ alloy. Motivated by these previous studies, the present work used an extensive scanning electron microscopy (SEM)-based approach to assess whether prior deformation could modify the GBCD and, hence, the DP reaction rate in an industrial Mg-9Al-1Zn (wt.\%) alloy.

\section{Experimental}

The AZ91 alloy was provided by Hydro Aluminium R\&D, Bonn, in the form of $4.5 \mathrm{~mm}$ thick-rolled cast sheets. Before rolling and to dissolve the precipitates and, thereby, ensure solute homogenization, the material was solution annealed for $20 \mathrm{~h}$ at $725 \mathrm{~K}$. To prevent precipitation of the $\beta$-phase $\left(\mathrm{Mg}_{17} \mathrm{Al}_{12}\right)$, rolling (with $80 \%$ thickness reduction) was carried out at $725 \mathrm{~K}$. The samples were heat treated for $10 \mathrm{~min}$ at $725 \mathrm{~K}$ between passes to stabilise the rolling temperature. After rolling, the samples were directly quenched in water, and the material was recrystallized at the same temperature for $72 \mathrm{~h}$.

To examine the DP reaction kinetics and the GBCD, the samples were aged from $20 \mathrm{~min}$ to $4 \mathrm{~h}$ at $473 \mathrm{~K}$. Microstructural investigations were performed in the mid-plane of the rolled sheets, the surface was prepared by grinding with progressively finer $\mathrm{SiC}$ paper and mechanical polishing with diamond suspensions of particles ranging in 
size between 1 and $3 \mu \mathrm{m}$. Subsequent etching at room temperature in a solution of acetic picral revealed the grain structure and DP. The maximum extent of the reaction front was calculated from the optical micrographs.

The macrotexture was determined in the mid-plane of the sheets for the as-received and deformed state, the incomplete pole figures $\left(5^{\circ} \leq \alpha \leq 75^{\circ}\right)$ were measured in the back reflection mode using an X-ray texture goniometer with $\operatorname{CoK} \alpha$ radiation. Electron backscatter diffraction (EBSD) analysis of the as-deformed samples was then performed to determine the microtexture. EBSD was conducted using a LEO 1530 FEG-SEM equipped with a HKL channel 5. To remove the deformed layer attributable to mechanical polishing, the samples were electropolished in a $75 \mathrm{ml}$ phosphoric acid and $135 \mathrm{ml}$ ethanol solution at room temperature using a voltage of $2.04 \mathrm{~V}$.

In the GBCD analysis, the angle/axe parameters were computed from the neighbouring grain pairs and compared with the output experimental values. We also took into consideration the deviation from the exact coincidence as expressed by the Brandon criterion: $\Delta \theta_{\mathrm{th}}=$ $15^{\circ} \Sigma^{0.5}$ where $1 / \Sigma$ is the coincidence site density in volume.

\section{Results and discussion}

Figures 1(a) and (b) show the microstructure of the alloy in as-received and as-deformed (80\% thickness reduction) states, respectively. The first micrograph reveals the semidendritic microstructure of the $\delta(\mathrm{Mg})$, solid solution and the $\gamma\left(\mathrm{Mg}_{17} \mathrm{Al}_{12}\right)$, intermetallic phase precipitated in the interdendritic spaces (dark phase). Figure 1b shows that nonachieved recrystallization resulted in a granular microstructure consisting of a bimodal distribution of grain sizes with mean values of 5 and $25 \mu \mathrm{m}$. The remaining small-sized grains constitute the residue of hot-deformed grains that exhibit the well-known necklace microstructure (Del Valle et al 2003).

The corresponding textures of both samples are presented in the $\langle 0002\rangle$ pole figures shown in figures 2(a) and (b). Although the texture of the as-cast structure is weak, the hot-rolled sample exhibits a well-developed basal texture consisting of the $\langle 0001\rangle$ crystal axis parallel to the normal direction of the sample. Figure $2 \mathrm{c}$ shows that recrystallization and subsequent grain growth annealing at $725 \mathrm{~K}$ for $72 \mathrm{~h}$ did not significantly alter the texture of the material, which remained basal texture with a very slight increase in the intensity.

Figures 3(b)-(d) presents the evolution of the microstructure of the supersaturated and precipitation-annealed AZ91 alloy at $473 \mathrm{~K}$ for $20 \mathrm{~min}, 65 \mathrm{~min}$ and $3 \mathrm{~h}$, respectively. The cells (dark phase) progressively invaded the sample with a volume fraction of 5, 25 and $60 \%$, respectively. In previous work, the macroscopic kinetics of DP in the same AZ91 alloy was determined at $473 \mathrm{~K}$ using in situ X-ray diffraction and Vickers microhardness measurements (Azzeddine et al 2009). The results showed that the kinetics can be well described by the Johnson-Mehl-Avrami law. The $n$, Avrami parameter indicated that precipitation proceeds by a mechanism of nucleation following site saturation. Bradai et al (1999) earlier reported similar results in $\mathrm{Mg}-\mathrm{Al}$ binary model alloys. However, DP was greatly retarded due to the occurrence of fine continuous precipitation. As a result, the material was never fully engulfed by DP cells unlike the $\mathrm{Cu}-\mathrm{Ni}-\mathrm{Sn}$ alloy previously described by Alili et al (2008).

Figure 3(a) shows the results of orientation imaging microscopy (OIM) of the studied grains in more or less the same region as the preceding figures. OIM was performed on the recrystallized sample at $725 \mathrm{~K}$ for $72 \mathrm{~h}$, which is considered the initial state of the precipitation reaction and EBSD analysis.

Using the EBSD angle/axis and Euler angles of the adjacent grains, the histogram of the measured misorientation angle distribution was plotted for the AZ91 hotrolled ( $80 \%$ thickness reduction) and recrystallized sample
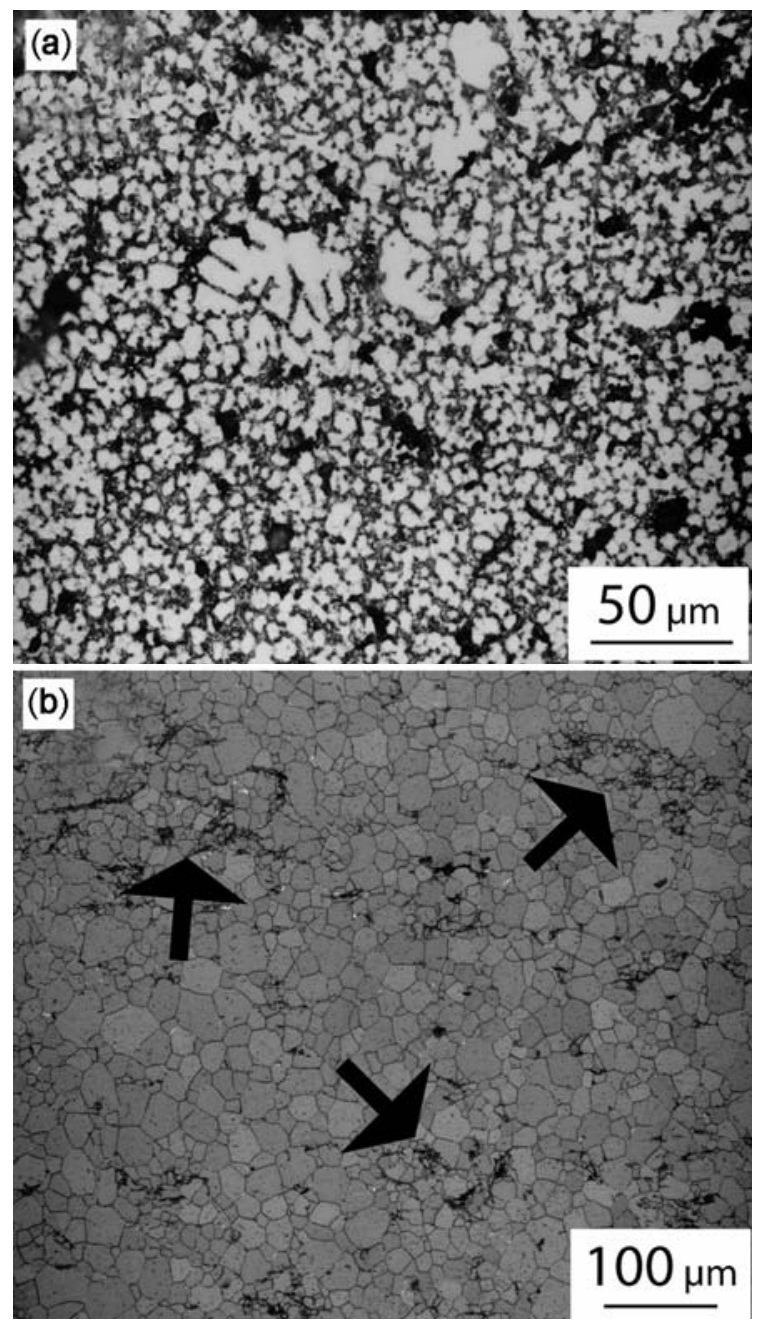

Figure 1. Microstructure of AZ91: (a) as-received and (b) hot rolled ( $80 \%$ thickness reduction). 

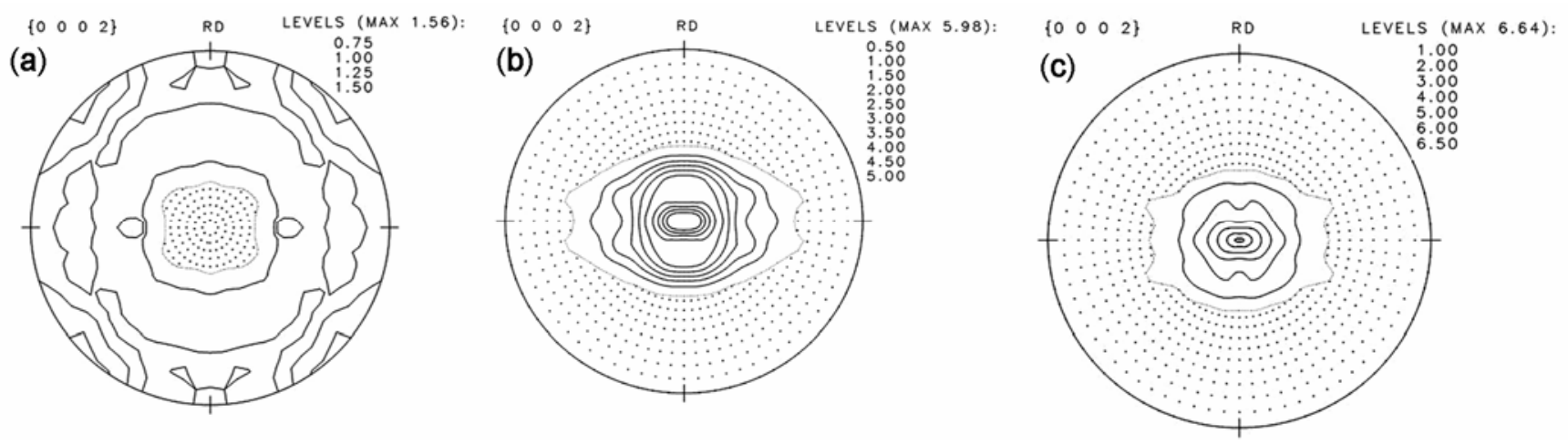

Figure 2. (0002) pole figure of the AZ91 alloy: (a) as-received, (b) hot rolled (80\% thickness reduction) and (c) hot rolled and recrystallized at $725 \mathrm{~K}$ for $72 \mathrm{~h}$.
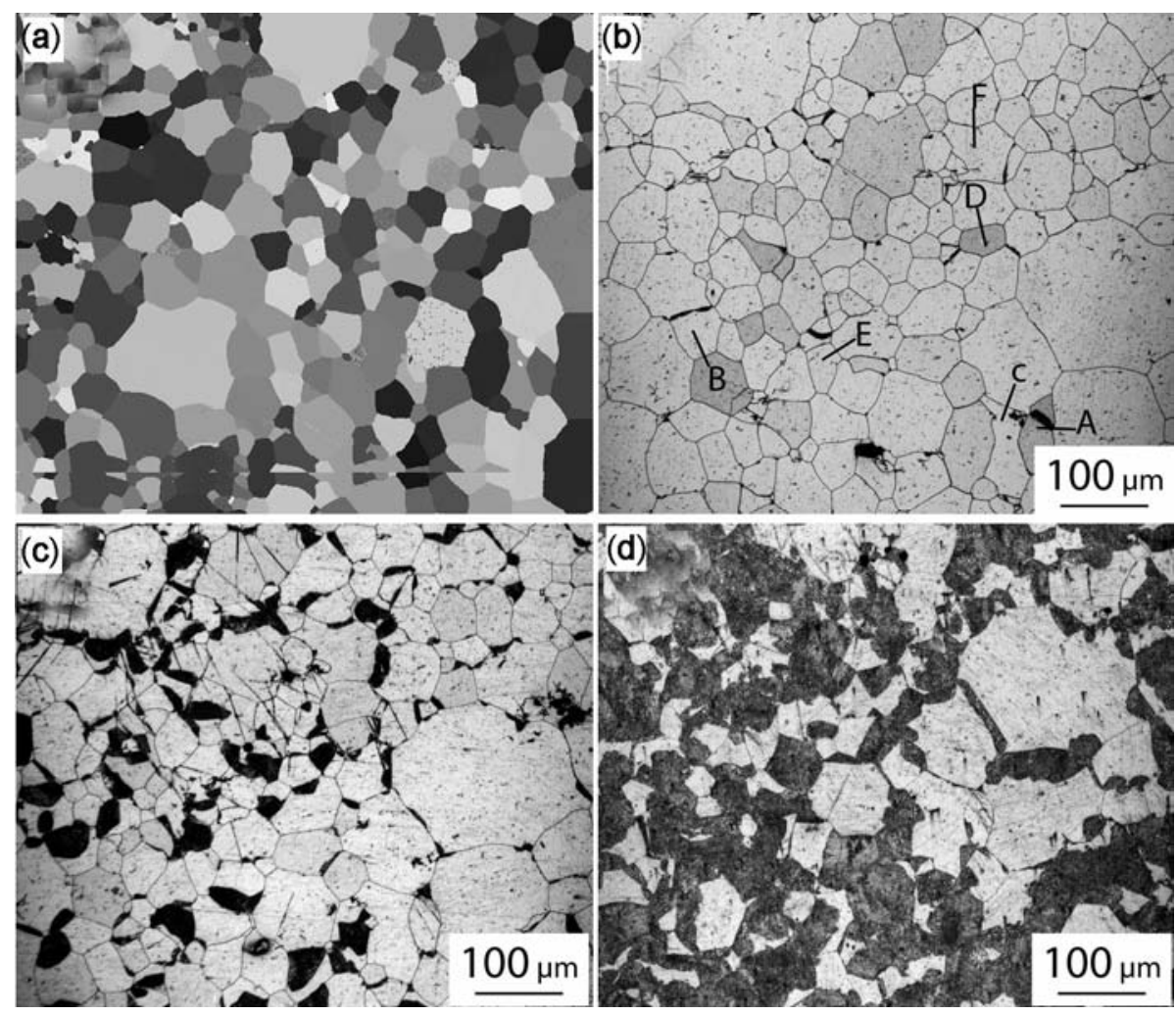

Figure 3. (a) OIM mapping of the AZ91 alloy sample hot rolled and annealed at $725 \mathrm{~K}$ for $72 \mathrm{~h}$ prior to DP heat treatment. Microstructure of AZ91 alloy sample annealed at $437 \mathrm{~K}$ for (b) $20 \mathrm{~min}$, (c) $65 \mathrm{~min}$ and (d) $265 \mathrm{~min}$. Near-CSL grain boundaries labelled A-D characteristics are presented in table 1.

(figure 4). Figure 4 shows that the distribution is not random and features a single peak with an average misorientation around $45^{\circ}$. The random distribution of the boundary misorientation was calculated using the approach of Morawiec (1995) and plotted in a dotted line. The resulting peak-shaped distribution is characteristic of basal fibre texture (figure 2b) obtained after rolling (Eddahbi et al 2005). The relative frequency of the misorientation angle below $15^{\circ}$ (LAGB) was less than $6 \%$. The figure also shows the low frequency of low-angle GBs contrary to earlier observations in cubic systems (Matsuoka et al 1994; Hirth and Gottstein 1998; Semenov et al 1998).

The observed maxima may be attributed to the probable presence of GBs with misorientations near ideal $\Sigma 14, \Sigma 35$ b around $\langle 210\rangle$ and $\Sigma 27, \Sigma 22, \Sigma 41$ around $\langle 100\rangle$ axis with angles of $44 \cdot 4,57 \cdot 1,38 \cdot 9,50 \cdot 4$ and $55 \cdot 8^{\circ}$, respectively. The occurrence of special grain boundaries (CSL) in hexagonal materials has been previously discussed 
Table 1. Part of the EBSD analysis of the grain boundaries shown in figure 3(b)-(d) (closest special CSL misorientation and deviation from it for AZ91 alloy).

\begin{tabular}{|c|c|c|c|c|c|c|c|}
\hline \multirow[b]{2}{*}{$\begin{array}{l}\text { Grain } \\
\text { boundary }\end{array}$} & \multicolumn{3}{|c|}{ Euler angles of adjacent grains } & \multirow[b]{2}{*}{$\Sigma$} & \multirow[b]{2}{*}{$\theta$} & \multirow[b]{2}{*}{$\langle h k l\rangle$} & \multirow[b]{2}{*}{$\Delta \theta_{\mathrm{exp}} / \Delta \theta_{\mathrm{th}}$} \\
\hline & $\begin{array}{c}\varphi 1 \\
\varphi^{\prime} 1\end{array}$ & $\begin{array}{c}\phi \\
\phi^{\prime}\end{array}$ & $\begin{array}{c}\varphi 2 \\
\varphi^{\prime} 2\end{array}$ & & & & \\
\hline A & $\begin{array}{r}153 \cdot 5 \\
12 \cdot 9\end{array}$ & $\begin{array}{r}6 \cdot 7 \\
57 \cdot 6\end{array}$ & $\begin{array}{c}54 \\
24 \cdot 8\end{array}$ & $\Sigma 18$ & $63 \cdot 9$ & $\langle 100\rangle$ & $1 \cdot 89$ \\
\hline B & $\begin{array}{r}17 \cdot 6 \\
147 \cdot 7\end{array}$ & $\begin{array}{l}44 \cdot 2 \\
73 \cdot 4\end{array}$ & $\begin{array}{c}8 \cdot 4 \\
59 \cdot 2\end{array}$ & $\Sigma 14$ & $48 \cdot 2$ & $\langle 210\rangle$ & $0 \cdot 94$ \\
\hline $\mathrm{C}$ & $\begin{array}{r}142 \cdot 6 \\
34 \cdot 5\end{array}$ & $\begin{array}{l}141 \cdot 6 \\
150 \cdot 4\end{array}$ & $\begin{array}{c}55 \\
7 \cdot 7\end{array}$ & $\Sigma 41$ & $54 \cdot 9$ & $\langle 100\rangle$ & $0 \cdot 42$ \\
\hline $\mathrm{D}$ & $\begin{array}{l}175 \cdot 8 \\
175 \cdot 8\end{array}$ & $\begin{array}{r}174.6 \\
69.9\end{array}$ & $\begin{array}{l}27 \cdot 9 \\
34 \cdot 9\end{array}$ & $\Sigma 18$ & $75 \cdot 4$ & $\langle 100\rangle$ & $1 \cdot 37$ \\
\hline $\mathrm{E}$ & $\begin{array}{r}29.9 \\
114.9\end{array}$ & $\begin{array}{l}70 \cdot 0 \\
55 \cdot 4\end{array}$ & $\begin{array}{l}38 \cdot 6 \\
21 \cdot 5\end{array}$ & $\Sigma 35 \mathrm{a}$ & $35 \cdot 9$ & $\langle 210\rangle$ & $0 \cdot 73$ \\
\hline $\mathrm{F}$ & $\begin{array}{r}175 \cdot 8 \\
19 \cdot 4\end{array}$ & $\begin{array}{l}69 \cdot 9 \\
99 \cdot 6\end{array}$ & $\begin{array}{l}34.9 \\
33.7\end{array}$ & - & $25 \cdot 39$ & $\langle 110\rangle$ & - \\
\hline
\end{tabular}

Note: The last column presents the deviation from the exact coincidence expressed by the Brandon criterion. The subscripts 'exp' and 'th' are relative to the experimental and the calculated deviations, respectively, from the special CSL.

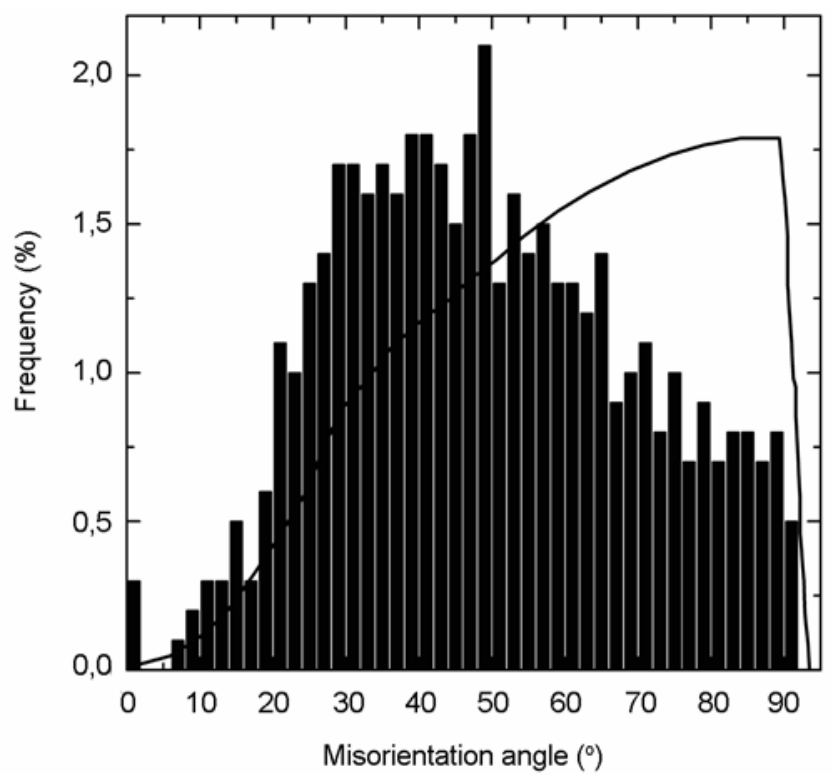

Figure 4. Histogram of the measured misorientation angle distribution for the AZ91 alloy hot rolled and recrystallized at $725 \mathrm{~K}$ for $72 \mathrm{~h}$. The line curve represents the density function for a random misorientation distribution (Morawiec 1995).

(Warrington 1975; Grimmer and Warrington 1983). Jäger et al (2006) presented a similar histogram to figure 4 for a commercial Mg (AZ31) alloy using a different mechanical forming process. They proposed that the occurrence of these misorientations obeys specific rules that involve the activation of twinning modes. In the present study, provided that the solute content has a negligible effect on the GBCD, the same rules may apply, leading to a similar misorientation distribution even if the $\mathrm{Al}$ solute content is not the same (9\% vs 3\%). It is well known that energetic, kinetic and geometric parameters influence the frequency of special GBs as a function of solute concentration. With increasing solute concentration, the influence of the energetics and kinetics is diminished. However, the impact of the geometric parameters on the GBCD is considered to be almost independent of the solute concentration (Palumbo and Aust 1995).

Table 1 presents some of the results of the EBSD analysis of the near-special misorientation of GB B, C and $\mathrm{E}$ and the random misorientation $\mathrm{A}, \mathrm{D}$ and $\mathrm{F}$. The latter GBs inhibit the DP reaction, whereas the former promotes the reaction. The second and third columns show the experimental Euler angles and the angle/axis representation of the GBs. The last column highlights the deviation from the exact coincidence expressed by the Brandon criterion; the subscripts 'exp' and 'th' denote the experimental and calculated deviations, respectively, from the special CSL.

Figures 5(a) and (b) show the measured displacement of the DP reaction front vs. the GB misorientation angle for the $\langle 100\rangle$ and $\langle 210\rangle$ rotation axis for the AZ91 alloy annealed at $473 \mathrm{~K}$ for 20,65 and $265 \mathrm{~min}$. It is clear from both figures that the displacement of the DP cell is not observable or very small, even for $265 \mathrm{~min}$, in special GBs close to $\Sigma 38, \Sigma 41$ and $\Sigma 18$ around the $\langle 100\rangle$ axis and to $\Sigma 35 \mathrm{a}, \Sigma 35 \mathrm{~b}$ and $\Sigma 10$ around the $\langle 210\rangle$ axis. This finding demonstrates that most of the CSL GBs analysed are inactive and that the DP reaction occurred at four of five GB CSL boundaries (Bradai et al 2002). The highest 
displacement was observed at misorientation angles around $35^{\circ}$ for $265 \mathrm{~min}$ of annealing. As pointed out previously by Shibayanagi et al (1990), the influence of the GBCD on the DP reaction depends on ageing conditions and the driving force of the reaction. This point is manifestly apparent in figures 3(b)-(d), with the number of grain boundaries from where the DP reaction occurred, increased with ageing time.

As previously noted (Bradai et al 2002), the small number of CSL boundaries is in agreement with earlier theoretical predictions concerning the occurrence of CSL GBs in hexagonal materials (Warrington 1975; Grimmer and Warrington 1983). According to Warrington (1975), not more than $10 \%$ of CSL GBs in cubic materials is found in hexagonal materials. Bradai et al (2002) previously reported that only five GBs, or $2 \%$ of all GBs studied, have a special CSL description and that the DP reaction occurred at four of five CSL boundaries. In this
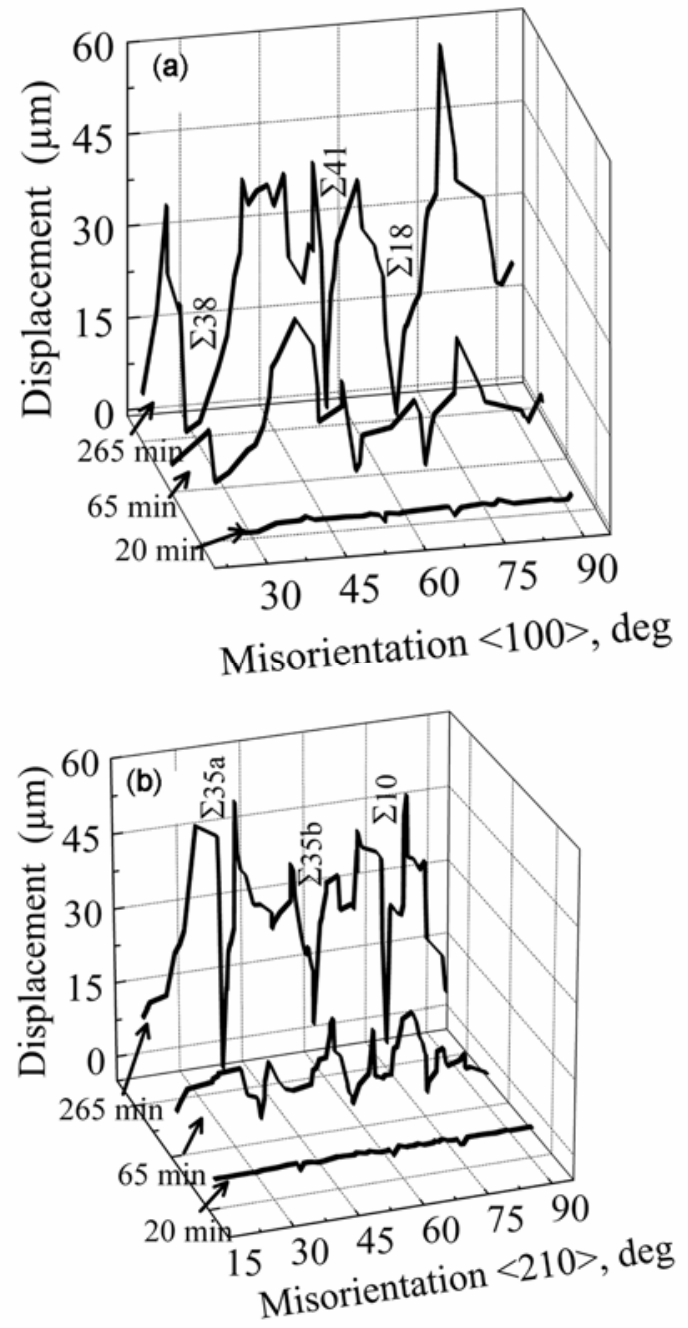

Figure 5. Displacement of the DP reaction front vs the GB misorientation angle relative to (a) $\langle 100\rangle$ and (b) $\langle 210\rangle$ rotation axis for the AZ91 alloy annealed at $473 \mathrm{~K}$ for 20,65 and $265 \mathrm{~min}$. study, the relative proportion increased to $4.7 \%$ (34 CSL GBs, of which seven of the 721 analysed were completely inactive).

Regarding the very slight difference between the present study and the previous one (Bradai et al 2002) in the frequency of the CSL GBs, prior deformation (hot rolling up to $80 \%$ thickness reduction) appears to have no effect on the frequency of special GBs. Several studies of cubic materials have shown that only special grain boundary engineering (GBE) processing can increase the fraction of special boundaries - typically between 0.3 and 0.6 in conventionally processed materials - to 0.8 (Schlegel et al 2009). Research has also been suggested that annealing may increase the fraction of special boundaries in highpurity metals but that this fraction decreases with grain growth in samples with impurities (Schlegel et al 2009). This idea can explain the low frequency relative to the expected frequency in pure hexagonal materials. In the present study of a commercial alloy with noticeable impurities and a grain size around $40 \mu \mathrm{m}$, the frequency was $4.7 \%$. In our previous study (Bradai et al 2002), the frequency was $2 \%$ using materials with less impurities and a grain size around $200 \mu \mathrm{m}$. Watanabe (1993) proposed that refinement of grains is effective in obtaining a high density of coincidence boundaries from the grain size dependence of GBCD, i.e. the fraction of low $\Sigma$ boundaries $(\Sigma 1-\Sigma 29)$ increases with decreasing grain size.

In figures 5(a) and (b), the displacement vs misorientation curves show local cusps and peaks at angles near special misorientation. However, we observed no cusps or peaks at misorientation angles corresponding to the other $\Sigma$ boundaries. Unfortunately, there are currently no published data on grain boundary energy curves vs misorientation angles for $\mathrm{Mg}$ or its alloy that can be compared with our results. Such a comparison had been reported previously for cubic systems. For example, Schmelzle et al (1992) reported that the variation of boundary velocity (vs misorientation angle) of diffusioninduced migration (DIGM) in a $\mathrm{Cu}(\mathrm{Zn})$ system was considerably similar to the dependence of the velocity of the migration front of the DP cell on the misorientation angle in synthetic $\mathrm{Cu}-\mathrm{Be}$ bicrystals (Monzen et al 2005).

\section{Conclusions}

Based on extensive SEM-based EBSD analysis of a commercial AZ91 alloy, we conclude the following:

(I) There is a net dependence of the DP reaction rate on the geometry of grain boundaries when the alloy sample is deformed (hot rolled) prior to ageing. The near special grain boundary is rather inactive, whereas most of the random high-angle boundaries promote the reaction.

(II) The fraction of special boundaries is very small and less than theoretical predictions. 
(III) Prior deformation (hot rolling up to $80 \%$ thickness reduction) has no effect on the frequency of special GBs.

\section{Acknowledgements}

One of the authors wishes to sincerely thank Pr. G Göttstein and Dr T Al-Samman from the Institüt für Metallkunde und Metallphysik, RWTH Aachen, for their assistance and help during her visits.

\section{References}

Alili B, Bradai D and Zieba P 2008 Mater. Character. 59 1526

Azzeddine H, Abdessameud S, Sari A, Alili B and Bradai D 2009 Phys. Chem. News 49109

Bischoff E, Semenov V, Rabkin E and Gust W 1998 Mater. Sci. Forum 273-275 243

Bradai D, Kadi-Hanifi M, Zieba P and Kuschke W M 1999 J. Mater. Sci. 345331

Bradai D, Zieba P, Bischoff E and Gust W 2002 Mater. Chem. Phys. 78222

Del Valle J A, Perez-Prado M T and Ruano O A 2003 Mater. Sci. Eng. A355 68

Eddahbi M, Del Valle J A, Perez-Prado M T and Ruano O A 2005 Mater. Sci. Eng. A410-411 308
Grimmer H and Warrington D H 1983 Z. Krist. 16288

Hirth S and Gottstein G 1998 Acta Mater. 263975

Jäger A, Lukác P, Gartnerová V, Haloda J and Dopita M 2006 Mat. Sci. Eng. A432 20

Lesuer D R and Kipoures G T 1995 J. Mater. 717

Matsuoka S, Mangan M A and Shiflet G J 1994 in Proceedings of the International conference on solid-solid phase transformations (eds) W C Johnson, J W Howe, D E Laughlin and W A Soffa (Warrendale, PA: The Minerals, Metals and Materials Society) p. 521

Monzen R, Watanabe C, Mino D and Saida S 2005 Acta Mater. 531253

Morawiec A 1995 J. Appl. Crystallogr. 28289

Palumbo G and Aust K T 1995 Can. Metall. Quart. 34 165

Randle V 1993 The measurement of grain boundary geometry (eds) B Cantor and M J Goringe (Bristol: Institute of Physics Publishing) p. 104

Schlegel S M, Hopkins V and Frary V 2009 Scripta Mater. 61 88

Schmelzle R, Giakupian B, Muschik T, Gust W and Fournelle R A 1992 Acta Metall. Mater. 40997

Semenov V, Rabkin E, Bischoff E and Gust W 1998 Acta Mater. $\mathbf{4 6} 2289$

Shibayanagi T, Kitazume Y and Hori S 1990 J. Japan Inst. Metals 54131

Warrington D H 1975 J. Phys. 3687

Watanabe T 1993 Texture Microstruct. 20195 